\title{
$O$ avesso do direito à literatura: por uma definição de literatura indígena
}

Tarsilla Couto de Britto ${ }^{1}$

Sinval Martins de Sousa Filho ${ }^{2}$

Gláucia Vieira Cândido ${ }^{3}$

\section{Uma história da invisibilização indígena: "raça extinta"}

A literatura indígena no Brasil possui várias histórias. A mais facilmente identificável é aquela em que o índio foi sagrado heróicavaleiro nas narrativas de cunho épico do final do século XIX. Quando se fala em literatura indígena no Brasil hoje, o senso comum, principalmente aquele pautado pelo letramento literário escolar, evoca o jovem guerreiro tupi de Gonçalves Dias (1851), que solenemente pedia: "Meu canto de morte, guerreiros ouvi!". Ou "a bela tabajara de cabelos mais negros que as asas da graúna", de José de Alencar (1865).

Qualquer iniciado nos estudos literários, bem como qualquer autor de literatura nativa que tem lutado pelo reconhecimento de sua arte, contudo, apontará o equívoco: trata-se de literatura indianista, em que a população autóctone estabelecida anteriormente à colonização ou um seu representante foi transformada em tema, objeto, matéria narrada. A expressão "literatura indígena" ou "literatura nativa", como prefere o escritor indígena Olívio Jekupé (2009), por outro lado, pretende indicar uma apropriação original, em que o objeto assume o papel de sujeito autor, criador, artista.

$\mathrm{O}$ investimento estético na figura do indígena realizado pelos românticos brasileiros foi fundamental para o processo de emancipação da arte nacional, mas pouco contribuiu para o reconhecimento do valor autônomo da tradição oral da cultura ameríndia. Muito ao contrário: no texto que nossos intelectuais legitimaram como documento inaugural do Romantismo - o "Ensaio sobre a história da literatura no Brasil",

\footnotetext{
${ }^{1}$ Doutora em teoria e história literária e professora da Universidade Federal de Goiás (UFG), Goiânia, GO, Brasil. E-mail: tarsillacouto@gmail.com

${ }^{2}$ Doutor em letras e linguística e professor da Universidade Federal de Goiás (UFG), Goiânia, GO, Brasil. E-mail: sinvalfilho7@gmail.com

${ }^{3}$ Doutora em linguística e professora da Universidade Federal de Goiás (UFG), Goiânia, GO, Brasil. E-mail: glaucia.v@uol.com.br
} 
publicado por Gonçalves Magalhães em 1836 -, os primeiros povos desta terra são declarados "raça extinta" (Franchetti, 2007, p. 58). Do mesmo modo, José de Alencar desaparece com os índios da paisagem tropical no afã de poder afirmar um passado lendário ao Brasil. Para que Peri e I Juca Pirama fossem Ulisses, Édipo ou Lancelot, os românticos extinguiram os nativos de sua terra pela segunda vez.

$\mathrm{Na}$ chamada fase interpretativa da formação do povo brasileiro, de Gilberto Freire a Darcy Ribeiro, todos aqueles que defenderam a tese da miscigenação participaram da terceira morte dos indígenas brasileiros. No plano étnico-cultural, a miscigenação se daria a favor da gestação de uma etnia nova, que teria unificado, na língua e nos costumes, os índios desengajados de seu viver gentílico, os negros trazidos da África e os europeus aquerenciados nas terras de Santa Cruz. A teoria da "mestiçagem", até então em voga, fundamentou um currículo desvinculado da realidade cultural brasileira, como assinala Silva (2010).

Depois disso, ainda levaríamos quase 50 anos para aceitá-los como cidadãos com direitos. A mentalidade eurocêntrica herdada da colonização retardou as consequências de experiências como a dos irmãos Vila Boas na década de 1940 e do desenvolvimento de disciplinas como a antropologia e a etnolinguística. Provas podem ser encontradas nas fotografias que documentam a existência de campos de concentração indígenas em nosso passado recente de ditadura militar (Campos, 2014).

\section{Políticas públicas de resgate dos direitos indígenas}

Felizmente, a Constituição Brasileira de 1988 garantiu premissas que permitem a correção de tantas injustiças. Conforme Sousa Filho (2016), os artigos 210 e 231, dos caps. III e VIII, respectivamente, da referida Carta são considerados por especialistas na área e pelos próprios indígenas como um marco importante na história desses povos no Brasil. O artigo 231 trata do direito à terra, enquanto o 210, da educação.

Também a Lei $\mathrm{n}^{\circ}$ 9.394, de 20 de dezembro de 1996 - Lei de Diretrizes e Bases da Educação Nacional (LDB) - traz, em seu art 78, as seguintes orientações para a educação indígena: “A União, com a colaboração das agências de fomento à cultura e de assistência aos índios, desenvolverá programas integrados de ensino e pesquisa para a oferta da educação escolar bilíngue e intercultural aos povos indígenas" (Brasil, 1996, p. 27). 
Notoriamente, houve todo um movimento dos indígenas, disparado por suas lutas anteriores à Constituição de 1988, que tomou corpo no Brasil após a promulgação da Carta Magna. Esse movimento alcança também a literatura. Essa literatura - que, segundo Novais (2014), até há bem pouco tempo, era chamada de literatura nativa, literatura das origens, literatura ameríndia e literatura indígena de tradição oral - tem recebido atualmente a denominação de literatura indígena.

Junto ao esforço pelo reconhecimento da literatura indígena, a Lei $\mathrm{n}^{\circ}$ 11.645, de 10 de março de 2008, aparece como referência para o movimento de escolarização dessa literatura. Essa lei oferece instrumentos jurídicos para a defesa do imaginário indígena ao instituir a obrigatoriedade do estudo das histórias e culturas indígenas no contexto escolar brasileiro.

A Lei $\mathrm{n}^{0} 11.645 / 2008$ assume o papel de uma política pública de valorização da história e da cultura dos povos indígenas e também de uma micropolítica educacional para formação de professores. Além disso, as ações decorrentes dessa lei nos possibilitaram pensar no modo como são construídos os cânones literários e, nesse sentido, uma ação de repercussão nacional e de grande impacto para determinados setores da nação foi a instituição do Programa Nacional Biblioteca da Escola (PNBE) Indígena, em 2015.4

A implantação do PNBE Indígena, com a literatura infantil e infantojuvenil, ocorreu após muitas discussões iniciadas em todo Brasil, a partir

\footnotetext{
${ }^{4}$ Em 2007, a Faculdade de Letras (FL) da Universidade Federal de Goiás (UFG) deu início ao curso de Licenciatura Intercultural para Formação de Professores Indígenas, ocasião em que o professor Sinval M. Sousa Filho ministrou aulas sobre os temas contextuais "Línguas Indígenas" e "Português Intercultural". Em 2008, Sousa Filho participou de reuniões para discussão e aprovação da Lei $\mathrm{n}^{\mathrm{o}} 11.645 / 2008$, a qual trata da obrigatoriedade do estudo da história e da cultura afrobrasileira e indígena nas escolas do Brasil. Em 2011, a professora Gláucia V. Candido se tornou docente da FL e, desde então, também passou a atuar no curso de Licenciatura Intercultural. A professora Tarsilla C. Britto ingressou na FL em 2014 e, no mesmo ano, iniciou um estudo de sistematização da literatura indígena. Nesse contexto profissional, em 2015, os três professores reunimo-nos e decidimos ampliar nossos estudos acerca da literatura indígena. Para tanto, resolvemos inicialmente ofertar aos alunos da FL/UFG uma Prática Como Componente Curricular (PCC) à qual intitulamos A Lei no 11.645, de 10 março de 2008, e o PNBE - Indígena (2015) na construção de um cânone chamado de literatura indígena. A fim de alcançar todos os objetivos do projeto da PCC, nós a dividimos longitudinalmente em três etapas, sendo que cada uma delas deveria realizar-se, respectivamente, em 2015, 2016 e 2017. Para os interessados em participar da PCC, anualmente, foram disponibilizadas 15 vagas, as quais acabaram sendo ampliadas devido à procura, haja vista que o tema, no âmbito da FL da UFG, sempre suscitou interesse.
} 
de 2013, com a abertura ao tema instaurada pelo PNBE Temático de 2013 (Brasil, 2013). Na Lei n ${ }^{\circ} 11645$, lê-se as seguintes recomendações:

Art. 26-A. Nos estabelecimentos de ensino fundamental e de ensino médio, públicos e privados, torna-se obrigatório o estudo da história e cultura afro-brasileira e indígena.

$\S 1$ o O conteúdo programático a que se refere este artigo incluirá diversos aspectos da história e da cultura que caracterizam a formação da população brasileira, a partir desses dois grupos étnicos, tais como o estudo da história da África e dos africanos, a luta dos negros e dos povos indígenas no Brasil, a cultura negra e indígena brasileira e o negro e o índio na formação da sociedade nacional, resgatando as suas contribuições nas áreas social, econômica e política, pertinentes à história do Brasil.

$\S 2$ o Os conteúdos referentes à história e cultura afro-brasileira e dos povos indígenas brasileiros serão ministrados no âmbito de todo o currículo escolar, em especial nas áreas de educação artística e de literatura e história brasileiras (Brasil, 2013).

Como se pode interpretar, o segundo parágrafo do art. 26-A institui o dever de se ministrar conteúdos que contemplem a contribuição dos indígenas na construção da literatura nacional. Ocorre que, na atualidade, existe no contexto nacional uma literatura chamada de literatura indígena, isto é, não só há a contribuição de indígenas para a construção do acervo literário brasileiro, como também uma literatura feita por autores indígenas, a qual naturalmente vem somar-se à literatura já existente no Brasil. Visando, portanto, contemplar essa literatura nas aulas das escolas regulares do Brasil, foi que o governo instituiu o PNBE Indígena. Assim, entre janeiro e abril de 2014, esteve aberto o edital do PNBE Indígena que convocou:

editores para o processo de inscrição e seleção de obras de literatura sobre a temática indígena que, por meio das artes verbais, divulguem e valorizem a diversidade sociocultural dos povos indígenas brasileiros, bem como suas diversas e amplas contribuições no processo histórico de formação da sociedade nacional, no âmbito do PNBE (Brasil, 2014).

Em linhas gerais, no referido programa acredita-se que o encaminhamento das questões nacionais deve dar-se em regime democrático, no qual o processo de discussão tenha por base os seguintes conceitos: i) a possibilidade de participação de todos os 
segmentos da sociedade, operacionalizada pela negociação; ii) o processo de negociação deve se dar com o compromisso de transparência entre as partes e a observância de princípios éticos; iii) a diversidade de opiniões não apenas deve ser respeitada, mas trazida ao debate para enriquecê-lo e legitimá-lo; iv) o conflito é inerente à relação entre as partes sociais e deve ser entendido como indicador de diversidade, e não motivador de ruptura. Nessa direção, o PNBE 2015 considera, em seu item 1.1., que o referido Edital $^{5}$ tem, por objeto,

a convocação de editores para o processo de inscrição e seleção de obras de literatura sobre a temática indígena que, por meio das artes verbais, divulguem e valorizem a diversidade sociocultural dos povos indígenas brasileiros, bem como suas diversas e amplas contribuições no processo histórico de formação da sociedade nacional, no âmbito do PNBE (Brasil, 2015, grifos nossos).

Ainda com relação à Lei $\mathrm{n}^{0} 11.645 / 2008$, segundo relatório de consultoria elaborado por Silva (2013), a sanção dessa legislação implica mudanças nas práticas educacionais, no modo como a educação lida com o diverso. A relatora descreve o modo como muitas licenciaturas revisaram seus currículos para cumprir a lei; destaca e comenta a

\footnotetext{
${ }^{5}$ Diante do lançamento do PNBE 2015 e de sua realização em curso, iniciamos no mesmo ano a primeira etapa da Prática como Componente Curricular (PCC) intitulada "A Lei n ${ }^{\circ} 11.645$, de 10 março de 2008, e o PNBE - Indígena (2015) na construção de um cânone chamado de literatura indígena". A proposta dessa etapa da PCC centrava-se, então, na possibilidade de os estudantes conhecerem a Lei ${ }^{\circ} 11.645 / 2008$ e o Edital do PNBE 2015 para, a partir daí, realizarem uma análise do processo de "canonização" de uma literatura indígena do início do século XXI. Para tanto, durante aquela primeira etapa, mediamos processos de leituras dos alunos no que se refere aos textos dos documentos em questão, e também as análises de livros da literatura infantil e infantojuvenil que se intitulam livros de literatura indígena. Assim, nossa ideia foi incentivar os alunos para que conhecessem os documentos e os estudos que versam sobre literatura indígena e, especialmente, oportunizar a todos os estudantes momentos de contato com algumas das obras selecionadas pelo PNBE 2015 e também com outras. Esperávamos, assim, que pudessem não só conhecer o processo de criação do cânone como também analisar as obras que fariam parte da referida "canonização". Outro objetivo dessa etapa da PCC era suprir nossa expectativa de que a literatura indígena pudesse ser uma fonte significativa de formação aos nossos alunos, quisessem eles escolher enveredar-se pela crítica literária ou por outros caminhos possibilitados pelos estudos das línguas naturais e das linguagens. Nesse sentido, o presente texto constitui-se como uma primeira sistematização do processo que estamos vivendo. Pretendemos, assim, que se torne um canal para dar visibilidade aos estudos sobre literatura indígena e, consequentemente, para facilitar nossa inserção nesse campo de pesquisa para estabelecer as prováveis interlocuções que teremos a partir de sua publicação. Dessas discussões, outros resultados são almejados. No mínimo, esperamos consolidar planos da criação de uma disciplina denominada "Literatura Indígena" no âmbito da instituição em que atuamos e, quem sabe, até mesmo em outras faculdades de letras do Brasil.
} 
abertura de várias linhas de pesquisa relativas ao assunto na pósgraduação; mas, quando chega à análise específica do curso de Letras, observa a precariedade da discussão sobre "literatura indígena" ${ }^{6}$

Acreditamos que a Lei $n^{0} 11.645 / 2008$ e o PNBE Indígena inscrevem a "literatura indígena" nessa superfície contraditoriamente áspera e invisível dos estudos da linguagem, da cultura e da literatura. Uma lei que prescreve o ensino de literatura como forma de introdução à história e à temática indígena torna visível e incontornável uma pergunta da qual se foge sempre: “O que é literatura?" (e aqui ampliamos o contexto da questão e perguntamos "O que é literatura indígena?"). Não temos dúvidas de que discutir a legitimidade de uma produção verbal de pretensões políticas, e não apenas estéticas, revelase áspera porque negar a existência ou legitimidade à literatura nativa é afirmar a tradição literária como uma tradição opressora cuja única finalidade seria o exercício de poder.

\section{A literatura indígena existe?}

A literatura indígena está presente em diferentes âmbitos da vida social:

- sua classificação está presente nas fichas catalográficas das editoras e bibliotecas, validando-se como critério de indexação (Franca e Silveira, 2014);

- é possível enumerar autores indígenas autodeclarados: Graça Graúna, Bino Pankararu, Olívio Jekupé (os três já citados neste texto), Daniel Munduruku (2013), Douglas Diegues (2003), entre outros;

- há uma agenda de saraus de literatura indígena, os quais são promovidos anualmente, desde 2009, pela Casa das Rosas com curadoria de Deborah Goldemberg (Goldemberg e Cunha, 2010);

- uma rede de comentadores de literatura indígena foi formada, com os professores Maria Inês Almeida (Universidade Federal

\footnotetext{
6 As dificuldades apresentadas pela referida relatora sintetizam bem os limites da discussão feita no estado de Goiás, que ainda não colocou a lei em prática de modo efetivo, ao menos no que diz respeito ao aspecto literário. Nesses termos, sendo a Faculdade de Letras da Universidade Federal de Goiás (FL/UFG) uma das principais instituições formadoras de professores no estado, cremos que não será exagero afirmar nossa responsabilidade no pouco engajamento com que temos tratado do tema. Até onde sabemos, o que há de mais duradouro e concreto com relação ao trabalho com literatura indígena na FL/UFG é o nosso projeto de PCC, sobre o qual falamos na seção anterior.
} 
de Minas Gerais), Pedro de Niemeyer Cesarino (Universidade Federal do Rio de Janeiro) e Sergio Medeiros (Universidade Federal de Santa Catarina);

- estabeleceram-se prêmios e concursos como o Prêmio de Literaturas Indígenas das Américas, o Concurso Curumim Leitura de Obras de Escritores Indígenas (promovido pela Fundação Nacional do Livro Infantil e Juvenil - FNLIJ) e o Prêmio Comunidades Indígenas (Governo de Minas Gerais);

- a literatura indígena brasileira foi recebida como uma literatura de relevância na $35^{a}$ Edição do Salão do Livro de Paris, em 2015, quando o Brasil foi o país homenageado, tendo, dentre os autores brasileiros participantes convidados, três representantes da literatura indígena (Daniel Munduruku, Davi Kopenawa e Cristino Wapichana);

- a literatura indígena participa da rede de traduções que compõe o que se convencionou chamar de "República das Letras": Daniel Munduruku, por exemplo, de seus 45 livros, teve dois traduzidos para a língua inglesa;

- agentes da mídia contribuem para a fabricação de listas de literatura indígena (jornais Folha de S. Paulo e Estadão e revistas como Carta Educação (Thiél, 2016) e Emília - Educação - entre outros, lançaram listas com "dez livros imperdíveis de literatura indígena"); e

- por fim, políticas públicas como a Lei $n^{\circ} 11.645 / 2008$ e o PNBE Indígena estimulam o mercado editorial, o consumo e a recepção crítica dessa literatura.

Diante desse sistema que envolve tantos agentes, podemos afirmar com alguma segurança que a literatura indígena "existe". Resta, assim, problematizar/pesquisar suas características, suas manifestações, suas práticas, seus temas recorrentes. A princípio, mesmo conscientes da visão etnocêntrica de aplicação da teoria da literatura, uma forma de pensamento ocidental, seria produtivo investigar problemas de autoria indígena, como, por exemplo: de individualidade $x$ coletividade (e aqui devemos rememorar a fala de Olívio Jekupé, que, em entrevista a Deborah Goldemberg, afirma fazer sua literatura a partir de histórias conhecidas por todos na aldeia, mas fazer a sua literatura); de formas literárias (afinal, 
como as teorias dos gêneros reagiriam à produção indígena? A mimese seria um problema?); por fim, cabe questionar o que essa literatura nos traria como algo "estranho", "novo" ao nosso horizonte epistemológico.

Nesse momento, há um longo caminho que vislumbramos como extremamente produtivo; e para citar apenas uma possibilidade, vale lembrar os estudos sobre perspectivismo ameríndio inaugurados por Eduardo Viveiros de Castro. Acerca disso, esse estudioso disse em uma entrevista que, se Descartes nos ensinou, "a nós modernos, a dizer "eu penso, logo existo" - a dizer, portanto, que a única vida ou existência que consigo pensar como indubitável é a minha própria -, o perspectivismo ameríndio começa pela afirmação duplamente inversa: "o outro existe, logo pensa" (Castro, 2012, s.p.). Essa entrevista remete a outra, concedida à TV Cultura por João Paulo Rodrigues, índio urbano, ${ }^{7}$ descendente dos Kaingang. Para Rodrigues,

as palavras são importantes... que quando ele diz amigos, ele realmente está dizendo amigos. $\mathrm{Na}$ verdade, a razão é domesticada. A emoção é domesticada. A percepção também... A temática indígena na literatura é a re-educação da sensibilidade. Então, isso é muito mais profundo. Quando a gente vê a árvore, a gente vê a árvore e o tronco. O pajé, quando ele vê a árvore, o que será que ele vê, será que ali tem mais essência? (Rodrigues apud Goldemberg e Cunha, 2010, p. 126)

Assim, entraríamos em questões mais profundas: que desafios a literatura indígena trará para a formação do leitor? Que inflexões a literatura indígena produzirá nos estudos literários ocidentais? Para os objetivos deste artigo, discutimos apenas os critérios da autonomia e da autorrepresentação.

\section{O critério da autonomia}

Para dar início à primeira discussão, retomamos o texto "O direito à literatura" de Antonio Candido. O amadurecimento do debate sobre o direito à literatura deu-se, não custa explicitar, durante um regime que suspendeu importantes direitos civis. É muito significativo que Candido inicie seu texto com a constatação de uma contradição:

7 Os índios urbanos lutam por seu reconhecimento, sua existência nas cidades. Segundo o Instituto Brasileiro de Geografia e Estatística, há mais de 300 mil índios urbanos no Brasil (IBGE, 2010). 
em comparação a eras passadas, chegamos a um máximo de racionalidade técnica e de domínio sobre a natureza. Isso permite imaginar a possibilidade de resolver grande número de problemas materiais do homem, quem sabe inclusive o da alimentação. No entanto, a irracionalidade do comportamento também é máxima, servida frequentemente pelos mesmos meios que deveriam realizar os desígnios da racionalidade. Assim com a energia atômica podemos ao mesmo tempo gerar força criadora e destruir a vida pela guerra; com o incrível progresso industrial aumentamos o conforto até alcançar níveis nunca sonhados, mas excluímos dele as grandes massas que condenamos à miséria (Candido, 2011, p. 171).

$\mathrm{Na}$ sequência, o autor parte para seu maior desafio: definir a literatura como um direito. Construindo um raciocínio cuidadoso, que se pauta pela distinção entre bens compressíveis (dispensáveis) e incompressíveis (indispensáveis), Antonio Candido busca averiguar se a literatura, assim como a crença e a opinião (reconhecidamente bens incompressíveis à dignidade humana), corresponderia a necessidades profundas do ser humano de uma forma geral. Sem torneios retóricos, faz-nos reconhecer que não há vida humana que se desenvolva sem alguma espécie de fabulação (Candido, 2011, p. 176-177), seja ela narrativa, dramática ou poética, já que "ela se manifesta desde o devaneio amoroso ou econômico no ônibus até a atenção fixada na novela de televisão ou na leitura seguida de um romance".

Para o autor, a necessidade da literatura seria equivalente àquela do sonho, pois este promove o equilíbrio psíquico exigido pela vigília. Daí viria o caráter humanizador da literatura, que confirma outros traços já definidos como essenciais ao ser humano: o exercício da reflexão, a aquisição do saber, a boa disposição para com o próximo, o afinamento das emoções, a capacidade de penetrar nos problemas da vida, o senso da beleza, a percepção da complexidade do mundo, o cultivo do humor. Assim, concebida em sentido amplo, como uma tendência à fantasia e à fabulação, a literatura parece sim corresponder a uma necessidade universal. Sua satisfação definiria, portanto, um direito.

Os termos do debate complicam-se: o "direito à literatura", do título do estudo de Antonio Candido, explicita-se como um direito de acesso à literatura. Lembremos que inicialmente essa arte da linguagem foi definida como uma faculdade inerente ao homem, uma propriedade universal que abarcaria todas as criações realizadas "em 
todos os níveis da sociedade, em todos os tipos de cultura, desde o que chamamos folclore, lenda, chiste até as formas mais complexas" (Candido, 2011, p. 176). A possibilidade de compreensão do direito como um "direito de acesso" dá-se de forma sutil, na medida em que a palavra "literatura" ganha, ao longo do texto, uma definição mais teórica, ou seja, ela é uma:

(1) construção de objetos autônomos, com estrutura e significado; (2) forma de expressão, isto é, manifesta emoções e a visão do mundo dos indivíduos e dos grupos; (3) forma de conhecimento, inclusive como incorporação difusa e inconsciente (Candido, 2011, p. 178).

Com a primeira das três definições, revelam-se as costuras incômodas presentes no avesso dessa discussão, pois a literatura como construção autônoma não contempla qualquer tipo de criação verbal, ao contrário das outras duas exigências. Observem: ninguém negará a classificação de narrativa como literatura para E o mundo virou mar, mito de fundação do povo Tupinambá, ${ }^{8}$ levando-se em consideração que o texto manifesta a visão de mundo de um grupo e que se presta ao conhecimento tanto para o próprio povo quanto para o olhar estrangeiro (Prezia, 2014).

Em palestra para a Academia brasileira de Letras no Rio de Janeiro, a escritora potiguara Graça Graúna dizia, em abril de 2012:

nossa literatura contemporânea é um dos instrumentos de que dispomos também para refletir acerca das tragédias cometidas pelos colonizadores contra os povos indígenas; a literatura é também um instrumento de paz a fim de cantarmos a esperança de que dias melhores virão para os povos indígenas no Brasil e em outras partes do mundo. Fazer literatura indígena é uma forma de compartilhar com os parentes e com os não indígenas nossa história de resistência, nossas conquistas, os desafios, as derrotas, as vitórias ou como fizemos na roda de conversa de escritores e artistas indígenas rumo ao Fórum Rio +20; assim como fez, também, o parente Gersen Baniwa, ao perguntar no seu livro: o que precisamos saber a respeito dos povos indígenas no Brasil de hoje? Porque a palavra indígena sempre existiu, agradeço pela oportunidade que me deram de estar aqui, na esperança de cultivar o direito de sonhar e a liberdade de expressão, sempre. Que Nanderu nos acolha (Graúna, 2012, p. 275).

\footnotetext{
${ }^{8}$ Publicado pela editora Richmond, com texto de Benedito Prezia e ilustrações de Lolla Angelucci.
} 
Todavia, o critério da autonomia torna tudo mais difícil, porque prevê exatamente que a arte verbal, sendo expressão de visão de mundo e sendo fonte de conhecimento, não pretenda ser nada disso. Por outro lado, nenhum estudioso consciente das transformações vividas pelo pensamento sobre o literário irá sofrer com o reconhecimento de que a Odisséia, por exemplo, não foi "criada" seguindo exatamente o que hoje se chama literatura. ${ }^{9}$ No tempo de Homero, as aventuras de Ulisses e Aquiles formavam uma enciclopédia de valores para orientação do homem grego arcaico (Havelock, 1996). Nessa linha de raciocínio, Odisséia e Ilíada não tinham autonomia em relação ao mundo que foram criadas. Todavia, seriam, isto sim, formas primitivas que fundiam sabedoria, moral, regras sociais e arte. $\mathrm{O}$ objetivo com essas considerações passa longe de relativizar a definição de literatura ao ponto de dizer que tudo pode ser literário. Interessa mais o fato de que a história das ideias e das práticas de produção e circulação de arte nos oferece analogias interessantes para responder à pergunta "o que é literatura indígena?" Nesse contexto, é importante refletir sobre o modo como a escritora indígena Graça Graúna entende a autonomia da literatura indígena.

Ao tratar do sistema literário brasileiro, Graúna (2013) afirma que a literatura indígena possui um discurso literário "diferencialista", o qual é visto como traço de resistência da literatura indígena a qualquer enquadramento. Para Graúna (2013, p. 15), a literatura indígena contemporânea é "um lugar utópico (de sobrevivência), uma variante do épico tecido pela oralidade; um lugar de confluência de vozes silenciadas e exiladas (escritas)".

\footnotetext{
${ }^{9}$ Roberto Acízelo de Souza afirma que, com relação à palavra literatura, "podemos considerar dois significados históricos básicos: 1 . até o século XVIII, a palavra mantém o sentido primitivo de sua origem latina - litteratura - , significando conhecimento relativo às técnicas de escrever e ler, cultura do homem letrado, instrução; 2 . da segunda metade do século XVIII em diante, o vocábulo passa a significar produto da atividade do homem de letras, conjunto de obras escritas, estabelecendo-se, assim, a base de suas diversas acepções modernas. Quanto a essas diversas acepções modernas, cremos ser possível reduzi-las às seguintes: 1 . conjunto da produção escrita de uma época ou país (donde expressões do tipo "literatura clássica", "literatura oitocentista", "literatura brasileira" etc.); 2. conjunto de obras distinto pela temática, origem ou público visado (donde expressões do tipo "literatura infantojuvenil", "literatura de massa", "literatura feminina", "literatura de ficção científica" etc.); 3. bibliografia sobre determinado campo especializado do conhecimento (donde expressões do tipo "literatura médica", "literatura jurídica", "literatura sociológica" etc.)" (Souza, 1995, p. 45). Chama atenção o fato de que, segundo as duas definições citadas, a produção narrativa e em versos dos povos nativos não pode ser chamada de literatura.
} 
A autonomia da literatura indígena, ainda segundo a escritora, pode ser atestada também pela audiência a (d)essa arte. Nesse sentido, a literatura indígena está ancorada em um público leitor delimitado, isto é, "uma minoria que semeia outras leituras possíveis no universo de poemas e prosas autóctones" (Graúna, 2013, p. 15). Ou seja, a autonomia não está vinculada apenas a um sentido de universalidade, de aceitação generalizada; ela institui-se a despeito de uma recepção idealizada. Daí a percepção da existência de um público específico, que se constitui como campo oficial de recepção e que justifica a existência da literatura indígena.

Ainda em relação à autonomia, Graúna (2013) acentua a questão da autoria. ${ }^{10}$ De acordo com a estudiosa, o espaço denominado literatura indígena somente pode ser ocupado por escritores indígenas, na condição de sujeitos produtores de sua própria cultura. Essa proposta, vista como ação de resistência e de afirmação de identidades/alteridades, surge na literatura indígena como forma de contrapor o longo período em que o indígena figurou apenas como temática na literatura brasileira, independentemente do modo como figurou, ou seja, positiva ou negativamente.

Os escritores indígenas, segundo Graúna (2013), são agentes autorais de seus povos e, dessa maneira, sua incumbência é construir uma escrita própria da história de cada etnia representada nos livros. Isto é, a esses autores é delegada a tarefa de imprimir visões de identidade do povo nos escritos da literatura indígena. Esse traço inicia-se na assinatura do autor, a qual coincide, quase sempre, com o nome do grupo do escritor, por exemplo, os escritores Daniel Munduruku, Ailton Krenak, entre outros. Assim, ao construir uma obra literária, o escritor indígena revela ao mundo que,

apesar da falta do seu reconhecimento na sociedade letrada, as vozes indígenas não se calam. O seu lugar está reservado na história de um outro mundo possível. Visando à construção desse

\footnotetext{
${ }^{10}$ Apesar de não fazermos um estudo comparativo, reconhecemos que esse postulado de Graúna (2013) encontra correlato nas reflexões sobre literatura afro-brasileira/negra, como se pode ver a partir das seguintes afirmações de Duarte (2017, p. 9): “a instância da autoria como fundamento para a existência da literatura afro-brasileira decorre da relevância dada à interação entre escritura e experiência, que inúmeros autores fazem questão de destacar, seja enquanto compromisso identitário e comunitário, seja no tocante à sua própria formação de artistas da palavra".
} 
mundo, os textos literários de autoria indígena tratam de uma série de problemas e perspectivas que tocam na questão identitária e que devem ser esclarecidos e confrontados com os textos não indígenas, pois trata-se de uma questão muito delicada e muito debatida hoje entre os escritores indígenas (Graúna, 2013, p. 55).

Esse ato de revelação é possível por causa de algo que poderíamos chamar de "indianidade" de cada escritor/autor, ou seja, pela experiência singular de cada indivíduo por meio da qual é possível elaborar um conceito de identidade. Para Graúna (2013), a indianidade é caracterizada especialmente pelo amor à terra e pela relação entre identidade e alteridade. Para a escritora, não é possível postular uma literatura de autoria indígena sem o reconhecimento dos fenômenos de hibridização e heterogeneidades.

O hibridismo, segundo Canclini (1997), diz respeito à participação de uma obra em dois ou mais conjuntos, gêneros ou estilos. Nessa obra, os elementos são reunidos anomalamente com vistas a originar um terceiro elemento, o qual pode ampliar ou reduzir as características dos dois primeiros. Para o autor, esse "jogo" discursivo assemelha-se ao processo de transculturação. Quanto ao fenômeno das heterogeneidades, podemos dizer, em conformidade com Graúna (2013) e Canclini (1997), que ele se caracteriza como um processo cultural e literário pautado nas relações de conflito entre culturas.

Sem dúvida, a questão do hibridismo cultural bem como a da heterogeneidade da literatura indígena são temas fundamentais e merecem ser mais aprofundados. Afinal, concordamos que discutir a noção de "pureza" cultural corrobora para a desarticulação de ideias que defendem a simplificação hierarquizante das culturas, assim como o seu entendimento em categorias estáticas e uniformes, tal como defende Néstor García Canclini (1997), entre outros. Todavia, por questões de espaço, não aprofundaremos a discussão neste trabalho.

\section{O contraponto da autorrepresentação no espaço do contato}

O purismo identitário nos levaria a repetir o gesto platônico de recusa da arte poética para os povos indígenas, afinal sua produção parece não atender aos critérios de definição vigentes no Ocidente. Tal parece ser a conclusão do professor Marcos Natali, em texto que procura desmontar o discurso universalista de "literatura para todos". Ao batizar sua reflexão 
com o nome de Além da literatura, Natali (2006) instaura seu debate com o texto anteriormente discutido de Antonio Candido.

$\mathrm{O}$ ponto de partida gera incômodo porque nos faz enxergar um modus operandi que consideramos natural, tal como foi natural para os românticos declarar as populações nativas uma "raça extinta" para transformá-la em matéria literária. Diz Natali: “o esquema que fez a cultura se tornar categoria central do nosso pensamento retira toda a diversidade do outro para que possamos experimentá-lo" (Natali, 2006, p. 37). Ora, impor a forma literária como modelo de expressão da cultura indígena não seria uma forma de assimilá-la e, por fim, exterminá-la? Difícil reconhecer em nossas boas intenções humanistas uma subreptícia crueldade, não?

A argumentação de Marcos Natali, no entanto, silencia sobre o fato de que nós já estamos em contato, os processos de assimilação já se iniciaram, não há como defender práticas culturais puras. E se o fazemos pelos índios, afirmamos ainda mais uma vez nossa posição de senhores do conhecimento e da justiça. Não é gratuito que o autor termine seu texto perguntando: "o que aconteceria se, em um cenário hipotético, aquém ou além do literário, a literatura não coincidisse com a justiça? Em outras palavras, se tivéssemos que escolher entre a literatura e a justiça, onde ficaria nossa fidelidade?" (Natali, 2006, p. 43).

A crítica de Natali atualiza a crítica platônica, porém essa crítica está descolada da realidade em que vivemos. Não se pergunta a um povo que já conhece a literatura e faz dela um repertório de referências se ele quer, se ele "ainda quer", a literatura. Vejamos, então, a resposta de Eliane Potiguara em entrevista a TV Cultura:

Nós vínhamos, dentro dessa nossa cultura, e precisávamos escrever as nossas histórias, registrar as nossas fotos, recontar a nossa história, por quê? Porque vinham outras pessoas contando e não os indígenas, ou os netos, filhos dos indígenas. E essas pessoas começaram a dar uma outra cara à filosofia que precisava ser contada (Potiguara apud Goldemberg e Cunha, 2010, p. 136).

A justiça será um bem ou uma virtude pela qual sempre lutaremos, inclusive por meio da prática de ensinar literatura através de tudo que há de justo e de injusto nela. Afinal, a leitura literária reconstitui diferentes passados, possibilita o exercício da alteridade e cria horizontes de expectativa ao nos afrontar com a diferença. 
Assim, mesmo que os indígenas brasileiros, por meio da aquisição e do domínio da escrita, passem a fazer literatura nos moldes ocidentais, procurando atender aos critérios das instituições literárias (como o PNBE, os prêmios e feiras literárias), isso importa porque, com a autoria indígena, a produção de sentidos está a serviço da própria (res)subjetivação. Não há literatura sem discurso. As formas estéticas são instrumentos de que os indígenas se apropriaram para configurar suas identidades. Identidades entendidas aqui não como essência, mas como resultantes de processos de identificação do sujeito ao complexo de formações discursivas historicamente e ideologicamente determinadas.

A recente prática da escrita e sua correlata necessária, a criação literária por parte dos indígenas brasileiros, devem ser entendidas como a própria historicização da questão indígena - e aqui continua valendo a analogia com Homero. É reinterpretando simbolicamente seu passado que os povos nativos escapam da invisibilidade e do amordaçamento. A questão, para Natali (2006), é criticar a ideia de que a literatura deva ser considerada um universal, bem como condenar tanto a concepção humanista de educação como a proposta de que ela deva ser levada a "todos os povos". Nesse contexto, hipoteticamente, se um povo tivesse que escolher entre literatura e justiça, não duvidamos de que deveria escolher a justiça. Mas no horizonte em que nos movemos e agimos, ou seja, na história, as coisas não se dão assim. A literatura existe. Assim como a injustiça. E não será pelo discurso que declararemos a morte de uma ou de outra. As contradições da convivência e do contato precisam ser encaradas.

Trata-se, ao mesmo tempo de autorrepresentação, e esta é a grande novidade, no caso da (re)inserção das comunidades indígenas na cultura brasileira. Trata-se da possibilidade de sua palavra ser posta em circulação independentemente de sua presença corporal.

\section{À guisa de considerações e recomendações para trabalhos futuros}

Ao longo deste texto, discutimos a literatura indígena, ou seja, focalizamos seu status de arte, seu papel no cânone e os desafios que essa modalidade literária impõe aos leitores, aos professores leitores e, especialmente, aos futuros professores. 
Sabemos que a discussão não se esgota nas reflexões que tecemos neste texto. Afinal, há muito o que dizer sobre essa "nova" literatura, a qual vem tomando corpo volumoso a partir do PNBE Indígena. Vale ressaltar que mais de 900 obras foram inscritas no edital do PNBE Indígena 2015, o qual, sabemos, movimentou o mercado e, consequentemente, o setor econômico do país. Segundo consta na página on-line do Fundo Nacional de Desenvolvimento da Educação e no Edital do PNBE Indígena (Brasil, 2015), o Ministério da Educação e Cultura (MEC) deveria selecionar acervos literários com até 25 títulos, os quais deveriam ser distribuídos às escolas indígenas do país todo para uso no ano letivo de 2015. De fato, 25 obras foram selecionadas e deveriam ser distribuídas às escolas brasileiras. ${ }^{11}$

Ainda de acordo com o FNDE (2015), o PNBE Temático atendeu a 59.845 escolas brasileiras e se empenhou na publicação e distribuição dos acervos a cifra de $\mathrm{R} \$ 24.265 .820,34$. É mais ou menos esse o montante aprovado em 2014 para os gastos com o PNBE Indígena. Esperamos que, de fato, tais investimentos sejam empenhados em todas as etapas e que os acervos da literatura indígena cheguem às escolas.

Percebe-se que ainda há muito para discutir sobre esse processo. Não nos enveredamos por esse caminho de discussão dessa política pública e seus impactos financeiros. Também, não discutimos os vários alcances do PNBE. Alcaraz (2015), por exemplo, discute os efeitos do PNBE Temático 2014 nas políticas educacionais e chega à conclusão de que o referido edital se configura como mais uma política racista, pois,

apesar de neste artigo considerarmos alguns dos livros aprovados pelo PNBE 2013, o próprio edital do ano em questão e o edital temático de obras voltado aos povos indígenas de 2014, fica claro que a promoção e afirmações identitárias são seguidas para manter um status da branquidade (Alcaraz, 2015, p. 37642).

Nosso foco, como apontamos, em nossos objetivos, foi o de nos movimentar em torno das questões suscitadas pelas macro e micropolíticas relativas aos povos indígenas, especialmente aquelas que dizem respeito ao ensino de literatura e à prática de produção literária. Com isso, centramos

11 Até a data da finalização deste texto, essa distribuição ainda não havia se iniciado, bem como o resultado da seleção dos livros também não havia sido divulgado. 
nossas ações na compreensão em torno das atividades de definição da literatura indígena para verificar como se dá/dará sua inserção no cânone.

Finalmente, queremos enfatizar que, reconhecendo a literatura indígena como um fato, vale investir em seu potencial artístico e político, por meio de pesquisa de diferentes naturezas e de incentivo à criação. É por meio dela que os indígenas poderão continuar sua luta contra a subordinação, contra o processo de colonização ainda em curso, pois, como arte e na condição de política, ela se constitui como atividade de autorrepresentação e de desnaturalização das desigualdades socioculturais.

\section{Referências}

ALCARAZ, Rita de Cassia Moser (2015). Programa Nacional Biblioteca da Escola e racismo institucional: debate e reflexão. In: CONGRESSO NACIONAL DE EDUCAÇÃO - EDUCERE, 12., 26-29 out. 2015, Curitiba. Anais... Curitiba: PUC-PR. Disponível em: <http://educere.bruc.com.br/arquivo/pdf2015/16098_8547.pdf>. Acesso em: 8 fev. 2017.

ALENCAR, José de (1865/1976). Iracema. São Paulo: Ática.

BRASIL (1996). Lei $\mathrm{n}^{\circ}$ 9.394, de 20 de dezembro de 1996. Estabelece as diretrizes e bases da educação nacional. Disponível em: <https://goo.gl/oXee3>. Acesso em: 20 jan. 2017.

BRASIL (2014). Ministério da Educação. Fundo Nacional de Desenvolvimento da Educação. Edital PNBE Indígena 2014. Disponível em: <https://goo.gl/AoEMZ5>. Acesso em: 4 fev. 2017.

BRASIL (2015). Ministério da Educação. Fundo Nacional de Desenvolvimento da Educação. Edital PNBE Indígena 2015. Disponível em: <https://goo.gl/dpiAu3>. Acesso em: 7 mar. 2017.

BRASIL. Ministério da Educação. Fundo Nacional de Desenvolvimento da Educação - FNDE (2013). Edital PNBE Temático 2013. Brasília. Disponível em: <https://goo.gl/bzX9UT>. Acesso em: 8 mar. 2017.

CAMPOS, André (2014). Ditadura criou campos de concentração indígenas. Carta Maior, São Paulo, 2 abr. On-line. Disponível em: <https://goo.gl/VXjUmY>. Acesso em: 2 fev. 2017.

CANCLINI, Néstor García (1997). Culturas híbridas: estratégias para entrar e sair da modernidade. Tradução de Ana Regina Lessa e Heló́sa Pezza Cintrão. São Paulo: Edusp. 
CANDIDO, Antonio (2011). O direito à literatura. In: CANDIDO, Antonio. Vários escritos. 5. ed. Rio de Janeiro: Ouro sobre Azul. p. 171-193.

CASTRO, Eduardo Viveiros de (2012). "Só morto não tem outro": reflexões antropológicas de Eduardo Viveiros de Castro. Blog A Casa de Vidro, Goiânia, 5 jun. On-line. Disponível em: <https://goo.gl/rKbWz7>. Acesso em: 3 fev. 2017.

DIAS, Antônio Gonçalves (1851). I Juca Pirama. In: GONÇALVES DIAS, Antônio. Últimos cantos: poesias. Rio de Janeiro: F. de Paula Brito.

DIEGUES, Douglas (2003). Dá gusto andar desnudo por estas selvas. Curitiba: Travessa dos Editores.

DUARTE, Eduardo de Assis (2017). Por um conceito de literatura afro-brasileira. Portal Literafro, Belo Horizonte. On-line. Disponível em: <http:/ /150.164.100.248/literafro/data1/artigos/artigoeduardoassis2.pdf>. Acesso em: 6 set. 2017.

FRANCA, Aline; SILVEIRA, Naira Christofoletti (2014). A representação descritiva e a produção literária indígena brasileira. TransInformação, Campinas, v. 26, n. 1, p. 67-76. Disponível em: <https://goo.gl/zUMRJb>. Acesso em: 19 fev. 2017.

FRANCHETTI, Paulo (2007). Estudos de literatura brasileira e portuguesa. São Paulo: Ateliê.

GOLDEMBERG, Deborah; CUNHA, Rubelise da (2010). Literatura indígena contemporânea: o encontro das formas e dos conteúdos na poesia e prosa do I Sarau das Poéticas Indígenas. Espaço Ameríndio, Porto Alegre, v. 4, n. 1, p. 117148. Disponível em: <https://goo.gl/gBdqT3>. Acesso em: 3 fev. 2017.

GRAÚNA, Graça (2012). Literatura indígena no Brasil contemporâneo e outras questões em aberto. Educação E Linguagem, São Bernardo do Campo, v. 15, n. 25, p. 266-276. Disponível em: <https://goo.gl/59zHQN>. Acesso em: 2 fev. 2017.

GRAÚNA, Graça (2013). Contrapontos da literatura indígena contemporânea no Brasil. Belo Horizonte: Mazza.

HAVELOCK, Eric A. (1996). Prefácio a Platão. Tradução de Enid Abreu Dobránzsky, Campinas: Papirus.

IBGE - INSTITUTO BRASILEIRO DE GEOGRAFIA E ESTATÍSTICA (2010). Os indígenas no censo demográfico 2010: primeiras considerações com base no quesito cor ou raça. In: IBGE - INSTITUTO BRASILEIRO DE GEOGRAFIA E ESTATÍSTICA. Censo Demográfico 2010. Rio de Janeiro.

JEKUPÉ, Olívio (2009). Literatura escrita pelos povos indígenas. São Paulo: Scortecci.

MUNDURUKU, Daniel (2006). Parece que foi ontem. Ilustração de Mauricio Negro. São Paulo: Global. 
MUNDURUKU, Daniel (2013). Tales of the Amazon: how the Munduruku indians live. Groundwood Books.

NATALI, Marcos (2006). Além da literatura. Literatura e sociedade: Revista do Departamento de Teoria Literária e Literatura Comparada da USP, n. 9, p. 30-43.

NOVAIS, Carlos Augusto (2014). Literatura indígena. Glossário CEALE: termos de alfabetização, leitura e escrita para educadores. Disponível em: <https://goo.gl/8StVRZ>. Acesso em: 7 mar. 2017.

PREZIA, Benedito (2014). E o mundo virou mar... - Mito do povo tupinambá. Ilustração de Lolla Angelucci. Rio Branco: Richmond Educação.

SILVA, Beatriz Carretta Corrêa da (2013). Relatório final de consultoria. Projeto CNE/UNESCO 914BRA1136.3: desenvolvimento, aprimoramento e consolidação de uma educação nacional de qualidade - Ensino de história e cultura dos povos indígenas. Ministério da Educação. Conselho Nacional de Educação. Brasília. Disponível em: <https:/ /goo.gl/6YCKGL>. Acesso em: 3 fev. 2017.

SILVA, Maria da Penha da (2010). A temática indígena no currículo escolar à luz da Lei 11.645/2008. Cadernos de Pesquisa, São Luís, v. 17, n. 2, maio/ago. Disponível em: <https://goo.gl/AbosjR>. Acesso em: 20 fev. 2017.

SOUSA FILHO, Sinval Martins de (2016). Os processos formais e não formais de saberes e práticas dos Akwén-Xerente (Jê) na escola indígena. In: ORTIZPREUSS, Elena; COUTO; Elza K. K. N. do; RAMOS, Rui Manuel (Org.). Múltiplos olhares em linguística e linguística aplicada. Campinas: Pontes. p. 121-134.

SOUZA, Roberto Acízelo de (1995). Teoria da literatura. São Paulo: Ática.

THIÉL, Janice Cristine (2016). Dez obras para conhecer a literatura indígena. Carta Educação, São Paulo, 14 jan. 2016. Disponível em: <https://goo.gl/sR7hoC>. Acesso em: 19 fev. 2017.

Recebido em 10 de março de 2017.

Aprovado em 3 de setembro de 2017.

\section{resumo/abstract/resumen}

\section{O avesso do direito à literatura: por uma definição de literatura indígena}

Tarsilla Couto de Britto, Sinval Martins de Sousa Filho e Gláucia Vieira Cândido 
Este artigo discute de forma mais ampla a contribuição de indígenas para a construção do acervo literário brasileiro por meio da chamada "literatura indígena". De forma mais específica, o objetivo deste texto é lançar questionamentos acerca do direito à/da literatura indígena de pertencer ao cânone literário brasileiro e até internacional. A partir de uma pesquisa de cunho bibliográfico, apontam-se algumas reflexões sobre o modo como ocorrem ações para a criação de um cânone literário à luz de aspectos importantes da história da literatura brasileira no que respeita à figura dos personagens indígenas, da literatura indianista e da elaboração do cânone literário nacional. O texto destaca o lugar do critério de autonomia na definição desse cânone e também descreve caminhos percorridos e os que provavelmente serão percorridos pela literatura indígena para que ela seja reconhecida e faça parte do referido cânone literário. Os resultados mostram a literatura indígena firmando-se em meio ao cânone e revelam que os potenciais artísticos e políticos dessa literatura podem constituir-se como atividades de autorrepresentações das identidades dos povos indígenas e também como instrumentos para a desnaturalização das desigualdades socioculturais.

Palavras-chave: literatura, cânone literário brasileiro, literatura indígena.

\section{The reverse of the right to literature: for a definition of indigenous literature}

Tarsilla Couto de Britto, Sinval Martins de Sousa Filho and Gláucia Vieira Cândido

This paper discusses in a broad manner the contributions of indigenous people to the construction of the Brazilian literary canon through what is termed 'Indigenous Literature'. More specifically, the purpose of this text is to inquire into the right to and of an Indigenous Literature as part of the Brazilian as well as the international literary canon. Using primarily a bibliographical research methodology, the essay articulates some reflections on how the literary canon comes about in light of important aspects in the history of the Brazilian literature. These elements pertain to indigenous characters, Indianist literature and the elaboration of a national literary canon. The text highlights how autonomy serves as a criterion in the definition of canons and also describes the processes through which indigenous literature can attain recognition and inclusion into the literary canon. The results show how indigenous literature is being consolidated in the canon and reveal that the artistic and political potentials of this literature might be regarded as activities of self-representation of the identities of indigenous people and also as instruments for the denaturalization of sociocultural inequalities.

Keywords: literature, Brazilian literary canon, indigenous literature. 


\section{El revés del derecho a la literatura: por una definición de literatura indígena}

Tarsilla Couto de Britto, Sinval Martins de Sousa Filho y Gláucia Vieira Cândido

Este artículo discute de forma amplia la contribución de los indígenas a la construcción del acervo literario brasileño por medio de la llamada 'Literatura Indígena'. De forma más específica, el objetivo de este texto es hacer cuestionamientos acerca del derecho a/de la Literatura Indígena de pertenecer al canon literario brasileño e, incluso, internacional. A partir de una investigación bibliográfica, se apuntan algunas reflexiones sobre el modo como ocurren acciones para la creación de un canon literario a la luz de aspectos importantes de la historia de la Literatura Brasileña con relación a la figura de los personajes indígenas, de la Literatura Indianista y de la elaboración del canon literario nacional. El texto destaca el lugar del criterio de la autonomía en la definición de ese canon y también describe los caminos recorridos y los que, probablemente, serán recorridos por la Literatura Indígena para que sea reconocida y haga parte de ese canon. Los resultados muestran que la Literatura Indígena está afirmándose en medio del canon y revelan que los potenciales artísticos y políticos de esa literatura pueden constituirse como actividades de autorrepresentación de las identidades de los pueblos indígenas y también como instrumentos para la desnaturalización de las desigualdades socioculturales.

Palabras clave: literatura, canon literario brasileño, literatura indígena. 